\title{
ROGERS MCVAUGH \\ (30 DE MAYO DE 1909 - 24 DE SEPTIEMBRE DE 2009)
}

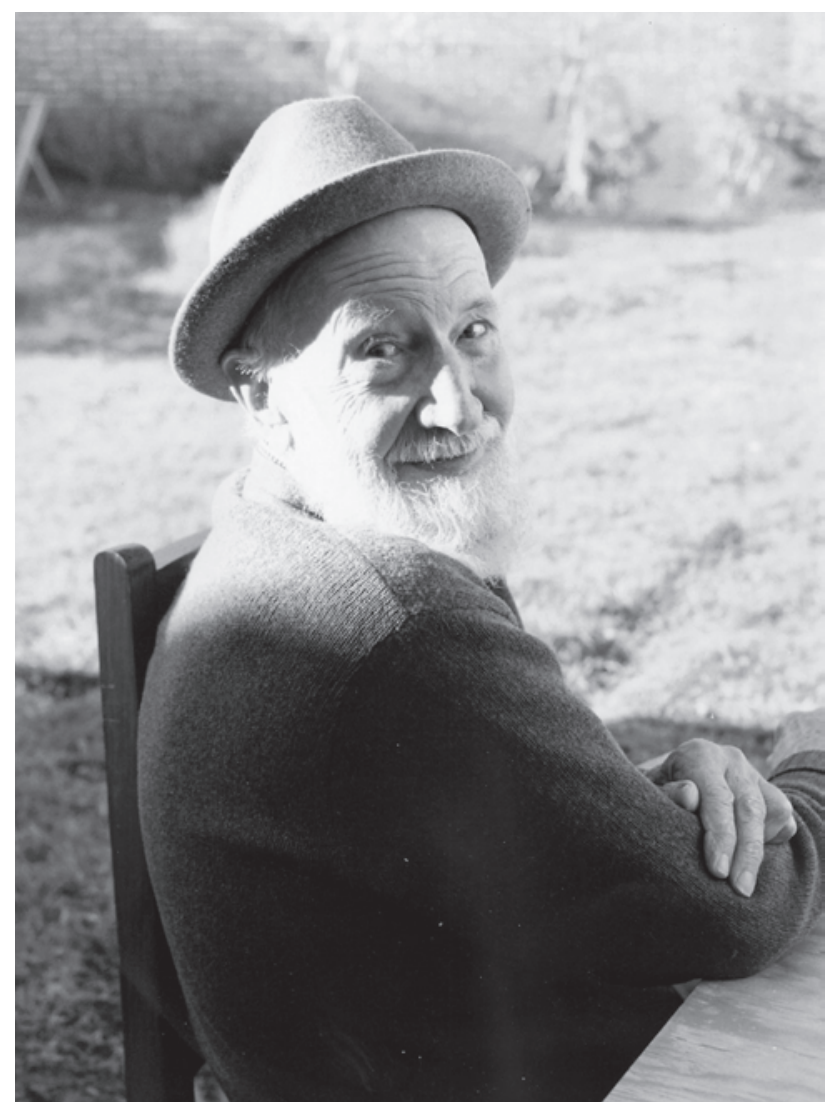

D ogers McVaugh nació en Brooklyn, Nueva York, hijo úniAco de Elizabeth y Roy McVaugh, maestros de escuela de Atlantic City. Obtuvo su licenciatura con honores en botánica del "Swarthmore College" en Filadelfia en 1931 y un doctorado en botánica de la Universidad de Pennsylvania en 1935, con un tema de tesis sobre el género Lobelia. Al concluir su doctorado formó parte de la Univerisidad de Georgia, donde conoció a Ruth Beall, con quien contrajo matrimonio y la familia se extendió con Michael y Jennifer, sus hijos.

Rogers McVaugh colectó sus primeros especímenes en Georgia desde el inicio de la década de 1930 hasta 1940 La mayoría de sus ejemplares los recolectó en Estados Unidos y México y se encuentran depositados en el Herbario de la Universidad de Michigan (MICH). Sin embargo, numerosos herbarios albergan también sus colecciones, como por ejemplo GA, US, UC, US y NY.

El Dr. McVaugh ocupó diversos puestos en universidades, comenzando con la Universidad de Georgia, Athens, en la cual fué profesor asistente (1935-1938). Posteriormente colaboró con el Departamento de Agricultura de los Estados Unidos (1938-1946). En la Universidad de Michigan, Ann Arbor, ocupó varias posiciones entre 1946-2009, como profesor asociado, profesor titular, profesor de botánica del programa Harley Harris Bartlett, curador de plantas vasculares del herbario MICH, director del mismo herbario, y se le otorgó la distinción de profesor emérito en 1979. Desde 1980 a 2009 colaboró en la Universidad de Carolina como profesor de botánica y también como curador de plantas mexicanas.

Recibió múltiples distinciones: de la Asociación Internacional de Taxonomía Vegetal, de la Sociedad Botánica de América, de la Sociedad Botánica de México (1978), del Jardín Botánico de Nueva York, de la Sociedad Americana de Taxónomos Vegetales y de la Universidad de Guadalajara. Obtuvo la medalla "Millenium” en el Congreso Internacional de Botánica en San Louis Missouri. Además, la medalla Cuatrecasas por excelencia en botánica tropical del Instituto Smithsoniano, y la Sociedad Botánica de América le otorgó el Centennial Award recientemente, en 2006.

Sus publicaciones comprenden 12 libros y 200 artículos sobre la historia de la botánica, florística y botánica sistemática. Su primer artículo de 1935 se tituló "Recent Changes in the Composition of a Local Flora" y su último se publicó en 2005 con el título "Marcus E. Jones in Mexico, 1892".

Para la botánica mexicana, su obra quizá más importante es "Flora Novo Galiciana”, en la que el Dr. McVaugh continuó trabajando ya entrado en sus noventa años de edad. Esta flora comprende varios volúmenes de una región muy diversa del oeste de 
México. En 1984 obtuvo la distinción "Henry Allan Gleason” por la Sociedad Botánica de América por este proyecto. Sus publicaciones relacionadas con la flora mexicana, iniciaron en 1952, con un recuento de plantas colectadas en una remota área de Querétaro. En ese año también publicó el inventario de zonas alpinas del Nevado de Colima y de la barranca de Guadalajara. En 1961 comenzó a publicar sobre la Flora Novo Galiciana con el tratamiento de las Euphorbiaceae, en la revista Brittonia. Publicó conjuntamente con Faustino Miranda un artículo sobre novedades de la flora de Jalisco en los Anales del Instituto de Biología de la UNAM. Su colaboración con Jerzy Rzedowski comenzó con la publicación del artículo sobre la 'Vegetación de Nueva Galicia", incluída en "Contributions to the Michigan Herbarium" en 1966. En 1972 publicó un artículo sobre "Compositarum mexicanarum pugillus". En los Anales de la Escuela de Nacional Ciencias Biológicas publicó junto con Jerzy Rzedowski "Nota sobre la flora del NE del estado de Aguascalientes (México)". Desde 1974 continuó publicando diversos tratamietnos sobre la Flora Novo Galiciana en "Contributions to the Michigan Herbarium", que incluyen familias my diversas tales como Compositae, Orchidaceae, Gramineae, Leguminosae y Bromeliaceae entre otras. Su más reciente publicación de Flora Novo Galiciana (2001) incluyó grupos como Ochnaceae, Loasaceae, Passifloraceae, Tiliaceae, Sterculiaceae, Bombacaceae, Malvaceae, Flacourtiaceae, Begoniaceae y Cucurbitaceae con la colaboración de varios coautores Es el autor de varios trabajos sobre las plantas colectadas en la expedición de Sessé \& Mociño de 1787-1803 en México.

Uno de sus amigos más cercanos, William R. Anderson, quien fué editor de la Flora Novo Galiciana escribió en 1979 (Rogers McVaugh, an Appreciaton. Taxon 28: 1-3): "El primer viaje de Rog a México se llevó a cabo en 1949, para estudiar capulines y quedó asombrado de que la flora del oeste del país no estuviera suficientemente colectada ni estudiada. De modo que el estudio de las plantas mexicanas ocupó el interés central de Rog, desplazando el estudio de Prunus y eventualmente cambiando a las Myrtaceae en sus afectos. Desde hace 30 años Rog ha llevado a cabo 12 expediciones a México, continuando con la práctica de estudiar plantas en sus habitats nativos. Rog nunca estuvo tan feliz como estar en el campo, acompañado de sus estudiantes".

Al cumplir noventa años de edad, Jerzy Rzedowsky y Ramón Cuevas nombraron una especie de Bursera en su honor, B. mcvaughiana (Acta Botánica Mexicana 46: 77-81. 1999), mencionando "El nombre del taxon nuevo se dedica como especial homenaje para conmemorar el 90 aniversario del nacimiento del Dr. Rogers McVaugh, incansable explorador e investigador de la flora de Jalisco y de Colima, principal autor de la Flora Novo-Galiciana, así como de una importante contribución al conocimiento de las especies de Bursera del occidente de México.

Victoria Sosa

Instituto de Ecología, A. C. 